\title{
Telomeres and telomerase
}

\author{
Simon R. W. L. Chan $\dagger$ and Elizabeth H. Blackburn* \\ University of California, San Francisco, Biochemistry and Biophysics, Box 2200, San Francisco, CA 94143-2200, USA
}

Telomeres are the protective DNA-protein complexes found at the ends of eukaryotic chromosomes. Telomeric DNA consists of tandem repeats of a simple, often G-rich, sequence specified by the action of telomerase, and complete replication of telomeric DNA requires telomerase. Telomerase is a specialized cellular ribonucleoprotein reverse transcriptase. By copying a short template sequence within its intrinsic RNA moiety, telomerase synthesizes the telomeric DNA strand running $5^{\prime}$ to $3^{\prime}$ towards the distal end of the chromosome, thus extending it. Fusion of a telomere, either with another telomere or with a broken DNA end, generally constitutes a catastrophic event for genomic stability. Telomerase acts to prevent such fusions. The molecular consequences of telomere failure, and the molecular contributors to telomere function, with an emphasis on telomerase, are discussed here.

Keywords: telomeres; telomerase; chromosome end-protection; telomere homeostasis

\section{INTRODUCTION}

Genomic stability and integrity must be maintained for an organism to function and propagate successfully. Telomeres are one of several key elements required for genomic stability (reviewed in Blackburn 1991, 2001). This was recognized in early work by McClintock and by Muller (McClintock 1938, 1941, 1942; Muller 1938; Muller \& Herskowitz 1954). McClintock's cytological discovery that normal chromosome ends lack the 'stickiness' of chromosome breaks dovetailed with Muller's inference that chromosome ends (the 'terminal genes') have a protective function based on his inability to isolate chromosomal terminal deletions. Thus, strikingly, both scientists, working respectively with maize and the fruitfly Drosophila melanogaster, converged on the finding that broken chromosome ends always fused with each other, but the telomeres never did. Hence, telomeres function to prevent chromosome fusions. McClintock showed that if a broken chromosome, with an end that lacks a telomere, is replicated, under certain circumstances the ends will fuse, and the two centromeres on the same chromosome can pull apart during anaphase, resulting in a new break caused by mechanical rupture as the chromosome bridge is stretched. The genetic consequences leading from such a breakage-fusion-bridge cycle are severe, because the breaks can occur at any position on the chromosome, causing irregular segregation of the genetic material into the two daughter cells.

This early cytogenetic work, starting from the 1930s, of course preceded the knowledge that the genetic material is DNA. More recent work shows that telomeres are protected from end-joining reactions that repair broken

\footnotetext{
*Author for correspondence (telomer@itsa.ucsf.edu).

$\dagger$ Present address: Molecular, Cell, and Developmental Biology, University of California Los Angeles, Los Angeles, CA 90095-1606, USA.
}

One contribution of 18 to a Discussion Meeting Issue 'Replicating and reshaping DNA: a celebration of the jubilee of the double helix'.
DNA: telomeres should never fuse to a double-stranded break in DNA. The specialized DNA-protein complex of the telomere is what distinguishes a natural chromosome end from a double-stranded DNA break. The 'capping' function of telomeres also protects chromosome ends against uncontrolled nucleolytic activity and excessive telomerase action.

It has become clear that compromising the telomeres puts the genome into jeopardy. Nevertheless, an important challenge that remains is to clarify what it is about telomeres that ensures their protective, chromosome end-capping functions are intact. Discussed here are how telomerase works, and some of the known factors that contribute to telomere capping. Conversely, ways in which telomeres can lose their protective function are reviewed. We describe recent findings on the effects of lack of telomerase in particular settings, as well as effects of mutating components of the protective telomeric DNA-protein complex.

\section{THE DNA END-REPLICATION PROBLEM}

Linear DNA molecules such as eukaryotic nuclear chromosomes require mechanisms in addition to the conventional DNA polymerases to complete the replication of their very extreme termini. The normal replication apparatus of cells carries out semiconservative DNA replication, copying a parental DNA strand as originally suggested by Watson and Crick in their famous 1953 Nature paper. Furthermore, all DNA polymerases can synthesize DNA only in the $5^{\prime}$ to $3^{\prime}$ direction, and DNA polymerases require a primer, usually an RNA or a DNA. As a result of these inherent properties, a consequence of the normal mechanism of semi-conservative DNA replication would be attrition of sequences from the ends of chromosomes, as shown in figure 1 . Without some other mechanism, it was predicted by Watson in 1972 that such attrition would eventually lead to loss of genetic information, preventing cells from continuing to multiply (cellular 'senescence'; Olovnikov 1973). 
linear chromosomes are not fully replicated by DNA polymerase
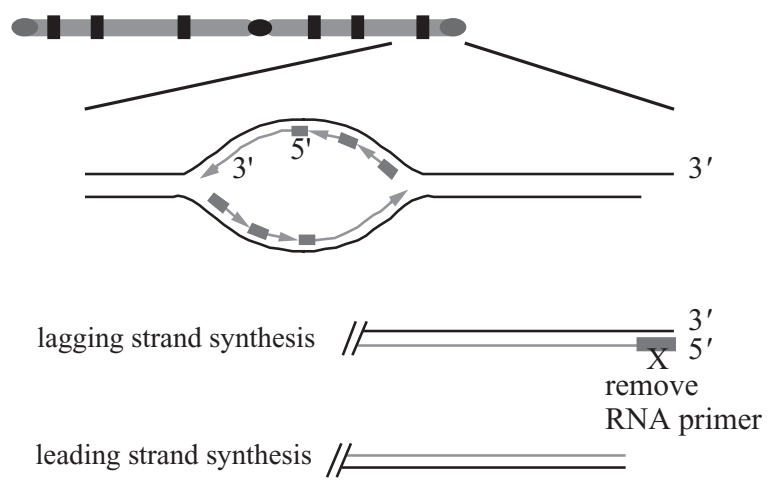

Figure 1. The DNA end-replication problem. The endreplication problem was defined by Watson and Olovnikov in the early 1970s, when it was realized that the requirement of all cellular DNA polymerases for a primer meant that DNA replicated by a lagging-strand mechanism would shorten, once the terminal RNA primer was degraded. This is depicted in more detail here. During the $\mathrm{S}$ phase, the chromosomal DNA is copied by a replication fork moving from an interior position on the chromosome towards the end of the linear chromosomal DNA molecule. Leading strand synthesis can theoretically copy the bottom parental strand all the way to its last nucleotide. Discontinuous lagging strand synthesis by polymerase-primase copies the top parental strand as shown, primed by RNA primers (thick blocks). The RNA primers are then removed, and the internal gaps are filled in by extension of the discontinuous DNA and ligation. However, removal of the most distal RNA primer leaves a $5^{\prime}$ terminal gap. Following subsequent rounds of DNA replication, if only the semi-conservative DNA replication machinery operates, as shown here, this gap will result in progressively shorter daughter strands.

Bacteria generally get around this problem by having circular chromosomal DNAs. Many bacteriophage and viruses with linear genomes bypass this problem in a variety of other ways: some use a circular or concatemerized DNA replication intermediate; others use a covalently attached terminal protein for a DNA priming. Some viruses, such as poxviruses, actually have the end of their linear DNA genome closed in a covalently closed loop, with replication proceeding all the way around the end of the loop, and then the two daughters separating by being cut apart (reviewed in Blackburn \& Szostak 1984). In contrast to these solutions, eukaryotic nuclear chromosomes use a very different mechanism to solve the problem of completing the replication of their ends: telomerase.

\section{TELOMERASE}

(a) An unusual way to make DNA

The discovery of telomerase provided the general solution to the end-replication problem in eukaryotes (Greider \& Blackburn 1985). Telomeric DNA consists of tandem repeats of a simple, often G-rich, sequence. This sequence is determined by the action of telomerase, which lengthens terminal regions of eukaryotic telomeric DNA by RNA-templated addition of the repeated DNA sequence. Complete replication of telomeric DNA requires telomerase. Telomerase was originally discovered by directed biochemical assays in vitro, using cell extracts and substrates designed to mimic telomeric DNA termini (Greider \& Blackburn 1985). This polymerization action was then shown to occur on natural telomeres in vivo (Yu et al. 1990). Initially called 'telomere terminal transferase' (Greider \& Blackburn 1985), the enzyme was subsequently dubbed 'telomerase' (Greider \& Blackburn 1987), by which name it has been known since then.

Telomerase is a specialized cellular RT. It is a ribonucleoprotein (RNP) complex and it synthesizes one strand of the telomeric DNA - namely, the strand running 5' to $3^{\prime}$ towards the distal end of the chromosome-by copying a short template sequence within its intrinsic RNA moiety (Greider \& Blackburn 1989; Shippen-Lentz \& Blackburn 1990; Yu et al. 1990). This action extends the 3' terminal, single-stranded overhang found at the ends of telomeric DNA (figure $2 a$ ). Discovery of this polymerization action of telomerase established the role of telomerase as a polymerase that extends one telomeric DNA strand. Synthesis of the complementary strand of the telomeric repeats is presumed to occur through lagging strand synthesis by the normal cellular DNA replication machinery. The resulting array of telomeric DNA repeats attracts and binds a set of DNA sequence-specific binding proteins. These in turn bind a further set of proteins to build an inferred higherorder complex nucleated on the telomeric DNA.

Addition of telomeric DNA onto chromosome ends by telomerase serves to counterbalance the losses predicted from the end-replication problem and from nuclease action (Wellinger et al. 1996), or potentially other DNA damage (Von Zglinicki 2002) at telomeric DNA ends. Interestingly, although the telomerase mechanism for telomere maintenance is very widespread among eukaryotes, and seems to have appeared early in eukaryotic evolution (Nakamura et al. 1997; Nakamura \& Cech 1998; Blackburn 1999; Blasco 2002), it is not completely universal. The best studied natural exception to the telomerasemediated mode of telomere maintenance is, ironically, $D$. melanogaster, the species for which the term telomere was originally coined by Muller. Drosophila melanogaster has no telomerase. Instead, it maintains its telomeres by periodic addition of large retroelements to the chromosomal ends, building a complex array of repeats that form heterochromatin at the chromosomal end regions (Pardue 1995). This chromosome-terminal heterochomatin provides the telomeric end protection. This was seen when a known heterochromatin protein, normally present at D. melanogaster telomeres, was mutated: such flies show frequent telomere-telomere fusions indicative of loss of end protection (Cenci et al. 2003).

The essential core components of the telomerase enzyme are the RT protein subunit TERT, and TER. TERT has several other essential telomerase-specific domains besides the RT domain (Nakamura \& Cech 1998). Telomerase in yeast and humans has been shown to be a dimeric complex containing two active sites, and with two telomerase RNAs and two TERTs that can functionally interact (see Ly et al. (2003a) and references therein), but it is not certain if dimerization is a universally conserved or even absolutely required feature of the enzyme. Genetics and biochemistry have revealed a number of other proteins which are associated with the core telomerase RNP (Blasco 2002). 


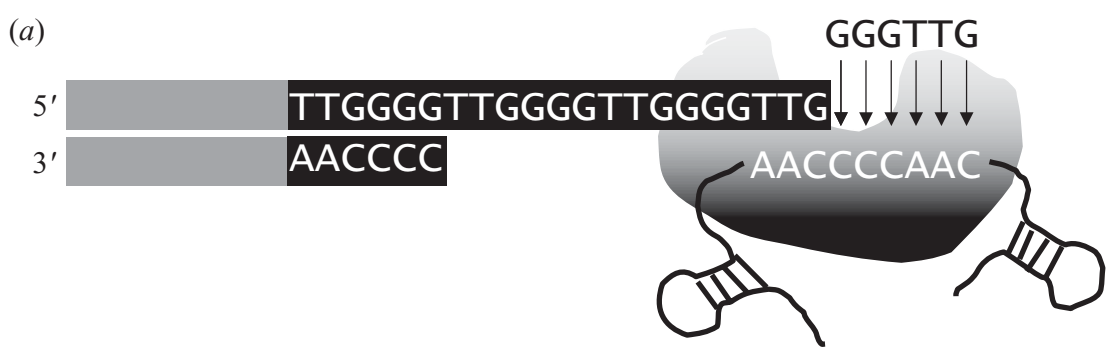

(b)

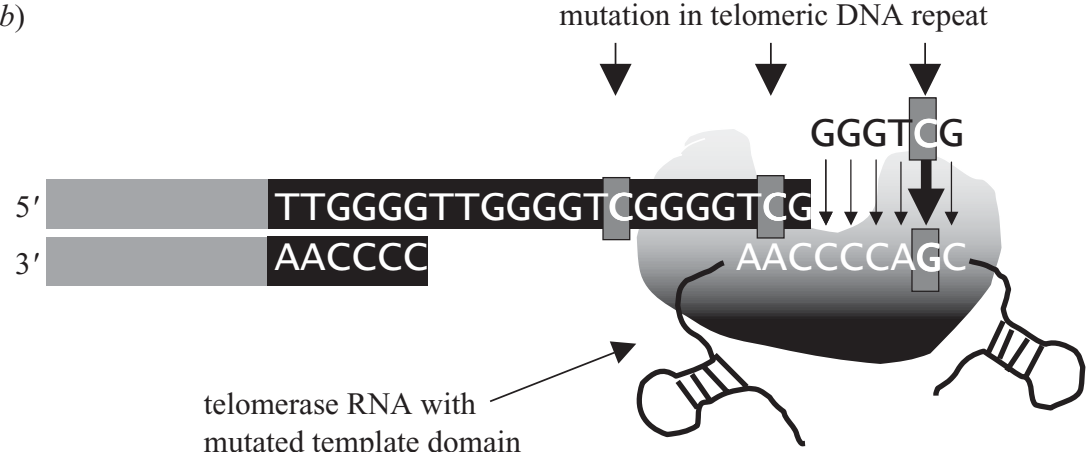

Figure 2. The DNA elongation action of telomerase. (a) Synthesis of telomeric DNA by the ribonucleoprotein enzyme telomerase from Tetrahymena thermophila. The $3^{\prime}$ few nucleotides of the G-rich overhang at the end of the chromosomal DNA (shown arbitrarily as ending in ...TTG-3') base pair with the telomere-complementary sequence in the telomerase RNA templating domain sequence. This chromosomal end is extended by polymerization of dGTP and dTTP using the RNA as a template, resulting in the addition of six telomeric nucleotides as schematically shown here. The extended DNA terminus unpairs from its RNA template, becoming available for another round of elongation by telomerase and/or to primasepolymerase, which uses it in turn as the template for lagging-strand synthesis of the C-rich telomeric strand. The protein RT subunit TERT and the RNA component TER of telomerase are indicated; only the RNA bases in the templating domain of TER are shown. (b) Mutation of a template base in telomerase RNA causes the corresponding mutation to be copied into telomeric DNA.

Nevertheless, we still do not have a full picture of all the components of the telomerase enzyme complexes or of how they regulate telomerase activity.

\section{(b) A role for RNA in telomerase enzyme activity}

The telomerase mode of DNA synthesis has some unprecedented properties. Initially, telomerase RNA was thought to have only a template role. All evidence indicates that the chemical step of the RT DNA polymerization reaction catalysed by telomerase is protein-based, mediated by the catalytic aspartate residues in the RT active site of TERT (Lingner et al. 1997). Mutant Tetrahymena telomerase RNA genes with altered residues within the 3'-AACCCCAAC-5' sequence, when introduced into Tetrahymena cells, caused the synthesis of the specifically altered telomeric repeats, demonstrating that specific residues in the RNA act as the template for telomere synthesis (Yu et al. 1990; figure 2b). Therefore, it was unexpected to find that the identity of the template and other telomerase RNA bases was also important for telomerase polymerization activity itself. This realization arose, initially, from making template mutations in telomerase: in addition to the expected changes in the telomeric DNA synthesized, certain mutations at specific RNA positions in the templating domain also led to aberrant behaviour of telomerase in vitro. For example, a $\mathrm{C}$ to $\mathrm{U}$ mutation at a central position in the template sequence of Tetrahymena telomerase RNA prevented telomere maintenance in vivo: the telomeres shortened, and after about 25 cell fissions following replacement of telomerase with the mutated RNA, the cells ceased to divide (Yu et al. 1990). In vitro analysis of this C48U mutant telomerase showed that it had a greatly increased rate (up to $50 \%$ under some conditions) of misincorporation of $\mathrm{dA}$ residues when copying the neighbouring $\mathrm{rC}$ residues in the template, which should have been copied into $\mathrm{dG}$ residues (Gilley et al. 1995). Specific mutations in the RNA templating domain of budding yeasts as well as Tetrahymena telomerase RNA also lead to various types of aberrant behaviour of telomerase in vitro, including different kinds of loss of enzymatic fidelity (Gilley \& Blackburn 1996; Prescott \& Blackburn 1997b; Lin et al. 2004).

In addition to causing misincorporation, the $48 \mathrm{U}$ mutant Tetrahymena telomerase was also very non-processive in vitro, with the elongating product prematurely dissociating from the template at a specific position: two nucleotides before the end of the template was reached. A premature dissociation at the same position in vitro was also caused by another point mutation, the C43A mutation, in the template RNA (Gilley et al. 1995). Small substitutions in the telomerase template sequence of Tetrahymena, or of budding yeasts including Saccharomyces cerevisiae, induce template slippage and/or premature termination, in which only one or a few bases are iteratively copied (Gilley et al. 1995; Prescott \& Blackburn 1997b; Lin et al. 2004; Tzfati et al. 2003). An even more dramatic effect on enzymatic activity was caused by a particular template mutation in $S$. cerevisiae telomerase RNA: a 
specific trinucleotide base substitution in the templating domain of this $c a .1 .3 \mathrm{~kb}$ RNA destroys enzymatic function (Prescott \& Blackburn 1997a,b). Hence base-specific interactions in the template region are critical for enzyme function.

Very little is understood about the nature of the RNA base-specific needs for telomerase. For example, Tetrahymena thermophila or human telomerases with the entire templating domain sequence substituted by a string of $\mathrm{rU}$ residues are still enzymatically active in vitro, synthesizing the predicted string of $\mathrm{dA}$ residues with reasonably high fidelity, albeit with very low processivity (Ware et al. 2000; Rivera \& Blackburn 2004). Surprisingly, these all-U template telomerase mutants caused no obvious telomeric or cell growth defect in Tetrahymena cells, and only a modest effect on growth of cultured human prostate cancer cells (Ware et al. 2000; Kim et al. 2001). By contrast, S. cerevisiae, with a telomerase RNA (TLC1) whose 16-base template sequence was constructed entirely of a string of $U$ residues (tlc1-U16), showed the gradual telomere shortening indicative of a telomerase null, and tlc1-U16 did not rescue in vivo replicative senescence of a TLC1 deletion mutant (S. R. W. L. Chan and E. H. Blackburn, unpublished data). This implies that an all-U template is not functional in $S$. cerevisiae telomerase RNA.

Curiously, in some species, even the wild-type telomerase shows a mode of template copying that suggests that properties not normally seen in template-directed polymerases may be normal in telomerase. These properties include limited and specific misincorporation events, and template slippage or stuttering as synthesis proceeds along the templating domain. For example, in the budding yeast $S$. castellii, a short sequence within the template frequently appears to be copied iteratively to produce variable numbers of a tandem dinucleotide repeat (Cohn \& Blackburn 1995). A similar mode of action also appears to underlie the normal action of $S$. cerevisiae telomerase, producing its hallmark variable numbers of TG repeats within its larger consensus repeat (Singer \& Gottschling 1994). In addition, this telomerase apparently frequently copies only part of its 16-base template. Paramecium telomerase regularly has an inbuilt misincorporation event occurring at a particular position in its template, to produce a mixture of GGGTTT and GGGGTT repeats (McCormick-Graham \& Romero 1996).

Thus, a characteristic of telomerases is that they appear to function at the edge of faithful template copying: indeed, in some species, even wild-type telomerase action routinely includes events that, in any other templatedirected DNA polymerase, would be classified as miscopying. Furthermore, it can take only a small perturbation-as little as a single telomerase RNA base substitution-to turn a normally high-fidelity telomerase into a highly error-prone polymerase. Hence base-specific interactions in the template cleft of the enzyme appear critical for enzyme function.

\section{(c) Influence of DNA as well as RNA on telomerase action}

As well as being highly susceptible to the influence of its RNA bases, telomerase is also not immune to the effects of its enzymatic product: single-stranded telomeric DNA. This DNA, as mentioned in $\ 3 \mathrm{a}$, is often but not always
G-rich. Interestingly, the $5^{\prime}$ portion of the DNA primer, even though it is not directly base-paired with the template, affects the reaction rate. A DNA primer with a Grich sequence stimulates the reaction rate kinetics by both increasing the $V_{\max }$ of the polymerization reaction and having a lower apparent $K_{\mathrm{m}}$ compared with non-G-rich primers (Lee \& Blackburn 1993). Thus, telomerase action is unusual for a DNA polymerase in being positively regulated by its product. These kinetic properties may also underlie its observed propensity to elongate telomeric DNA, as opposed to other sequences, in vivo.

\section{(d) Speculations on telomerase evolution}

Along with retroelements and retroviruses, telomerase constitutes another example of reversal of step one of the central dogma: DNA $\rightarrow$ RNA $\rightarrow$ protein. Furthermore, in the telomerase RNAs of various species, targeted, small, specific base mutations outside the template, as well as within it as discussed in $\ 3 \mathrm{~b}$, can also ablate telomerase enzymatic activity. A number of these mutations appear to interfere with telomerase enzymatic function directly, while not, for example, interfering with the ability of telomerase to assemble into a stable RNP (reviewed in Blackburn 2000a; Ly et al. 2003b). Thus, specific telomerase RNA base mutations can destroy enzyme function as effectively as mutating the catalytic aspartates of the RT active site of TERT protein. These findings emphasize that telomerase should be considered a true ribonucleoprotein enzyme.

As seen from the above description, telomerase presents a situation of an unusual mode of synthesis of an essential DNA, the telomeric DNA. As well as its enzymatic action constituting an interesting mechanism for DNA synthesis, telomerase raises provocative questions. Is the modern telomerase ribonucleoprotein a relic of an ancient, pre-DNA, RNA-based entity? Or is it a specialized derivative of an ancient all-protein RT, that only later in evolution acquired RNA to meet the eukaryote-specific need for telomere maintenance? Also, how did the modern-day retroviral and retroelement protein RTs evolve: was telomerase their cellular ancestor? In this regard it is worth noting that viral genes have generally been acquired from cellular sources: perhaps RTs are no exception.

\section{THE CHROMOSOMAL END-PROTECTION PROBLEM}

\section{(a) A dynamic model for telomere capping and} homeostasis

Broken DNA normally elicits a cell-cycle checkpoint response, followed by repair of the break by mechanisms that include non-homologous end-joining or homologous recombination. Telomeres need to be protected from these actions, a property called 'telomere capping'. Work done in many laboratories defines four distinguishable molecular readouts for telomere function that together comprise complete capping function: (i) preventing the telomere from eliciting a DNA damage response manifested as cell-cycle arrest or apoptosis; (ii) prevention of chromosome end fusions; (iii) prevention of homologous recombination between telomeric regions; and (iv) regulation of telomere length homeostasis. Loss of a functional telomeric cap can lead to failure of any one or more 
of these four normal properties of telomeres (reviewed in McEachern et al. 2000).

The higher-order complex formed by telomeric DNA and its sequence-specific binding proteins is critical for maintaining functional telomeres. Some minimal length of telomeric DNA repeat tract appears necessary to serve as the molecular scaffold capable of nucleating a higherorder DNA-protein complex that can protect the telomere. The functionality of the telomeric complex thus can be disrupted by telomere shortening. This happens, for example, in cells dividing in the absence of telomerase. Loss of telomere function leads to defects or blocks in chromosome segregation and hence to genomic instability (reviewed in Blackburn 2001). A primary role for telomerase, therefore, is to maintain the length of the tract of terminal telomeric DNA repeats. This maintenance is closely regulated. In dividing cells with active telomerase, telomeres are heterogeneous in length even within a single cell, but the population of telomeres is tightly controlled and kept within well-defined limits specific to that cell type (reviewed in McEachern et al. 2000).

The underlying mechanism for such telomere length homeostasis is to allow telomerase to act on telomeres as they shorten and, conversely, to limit its action to prevent their over-extension. The overall length of the telomeric DNA repeat tract, which serves as the molecular scaffold nucleating the higher-order DNA-protein complex of the telomere, is one important determinant of whether telomerase can access telomeric DNA for elongation. Several molecular and genetic experiments argue for a two-state model for normal telomeres (reviewed in Blackburn 2000b). This posits that the higher-order telomeric DNAprotein complex exists in a regulated and dynamic balance between two physical states: telomerase-accessible (uncapped) and telomerase-inaccessible (capped). A shortened telomere is acted on and elongated by telomerase. This increases its probability of switching to the capped state. Shortening occurs by incomplete replication rounds or degradation. This increases the probability of uncapping again. In yeast, telomerase acts only in the $S$ phase or G2/M in the cell cycle (Diede \& Gottschling 1999; Marcand et al. 2000). Therefore, this model predicts that the capping status of telomeres would temporarily change throughout the cell cycle. Indeed, the telomeric protein content does change in a cell-cycle-dependent fashion (Laroche et al. 2000; Smith et al. 2002).

\section{(b) Regulation of telomere length}

Experimentally, telomere length, not surprisingly, can be manipulated directly by changing the level of functional telomerase (Bodnar et al. 1998; Roy et al. 1998). Telomere length can also be altered by manipulating the levels of sequence-specific telomere binding proteins such as Rap1p (Conrad et al. 1990) or its partial functional counterparts, for example TRF1 in mammalian cells (Van Steensel \& de Lange 1997) or Taz1 in fission yeast (Cooper et al. 1997). These proteins, together with additional protein binding partners, negatively regulate telomere length by protecting telomeres from excessive telomerase action. Mutating the telomere DNA binding protein domain that is required to recruit other proteins to form the telomeric higher-order complex (or mutating these other proteins themselves) also causes telomeres to lengthen via telomerase action (Krauskopf \& Blackburn 1996; Marcand et al. 1997; Van Steensel \& de Lange 1997; Wotton \& Shore 1997; Kim et al. 1999). However, although they are known to be important, and thought to fold the telomeric DNA in some fashion, how these proteins determine the protective architecture of the telomeric complex is still unknown.

\section{(c) The very terminal DNA-protein complex of telomeres}

Functional/structural components that contribute to telomere capping include the higher-order telomeric DNAprotein complex, which requires some overall minimal length of the telomeric DNA tract as discussed in $\ 4 \mathrm{a}$. As discussed below, telomerase itself may also aid in capping chromosome ends, even without elongating the telomere population as a whole. But experiments show that one aspect of telomeres is especially critical for their protection and regulated elongation: the DNA-protein complex found on the terminal few repeats. This includes the DNA-protein complex formed on the single-stranded Grich strand DNA extension of the telomere. This complex (reviewed in Mitton-Fry et al. 2002) prevents this telomeric DNA end from setting off a cellular alarm bell-i.e. a DNA damage response. The double-stranded portion of the terminal few repeats also appears to be very important (Krauskopf \& Blackburn 1998; Smith \& Blackburn 1999). The importance of the very terminal part of the telomeric tract has been experimentally proved in two ways: either by mutation of the terminally binding proteins themselves, or by mutating the telomeric DNA through introducing mutations into the telomerase RNA template, causing mutant repeats to be added to the very tips of the telomeric tract. In either case, loss of telomere protective function and consequent cellular effects occur rapidly.

The first such experiments were done in the ciliate Tetrahymena. Certain small changes in the template sequence, which caused the corresponding sequences to be added to the telomeres, were found to rapidly diminish cell viability (Yu et al. 1990). Similar deleterious effects were subsequently shown in a budding yeast (McEachern \& Blackburn 1995). The potency and rapidity of these cellular viability effects, in two such distantly related organisms, prompted the testing of comparable telomerase RNA template mutations in human cancer cells. These cells, which express high endogenous levels of telomerase, were found to be highly susceptible to cell death upon even low levels of expression of mutant-template telomerase RNAs (Kim et al. 2001).

\section{(d) Disrupting telomere protection by telomerase RNA template mutations}

The coevolution of telomerase and the telomeric tract sequences presents an interesting problem: the cell not only must meet the requirements for the correct bases in telomerase RNA to support telomerase activity, but also needs the right DNA sequence to bind protective proteins at the telomeric tips. As was described in $\ 3 \mathrm{~b}$, certain template changes can alter telomerase activity. Of these, notably, a specific three-base substitution (the tlc1-476 GUG mutation) within the 16-base template of this yeast telomerase RNA led to loss of detectable in vitro telomerase activity in extracts made from the haploid tlc1-476 mutant 


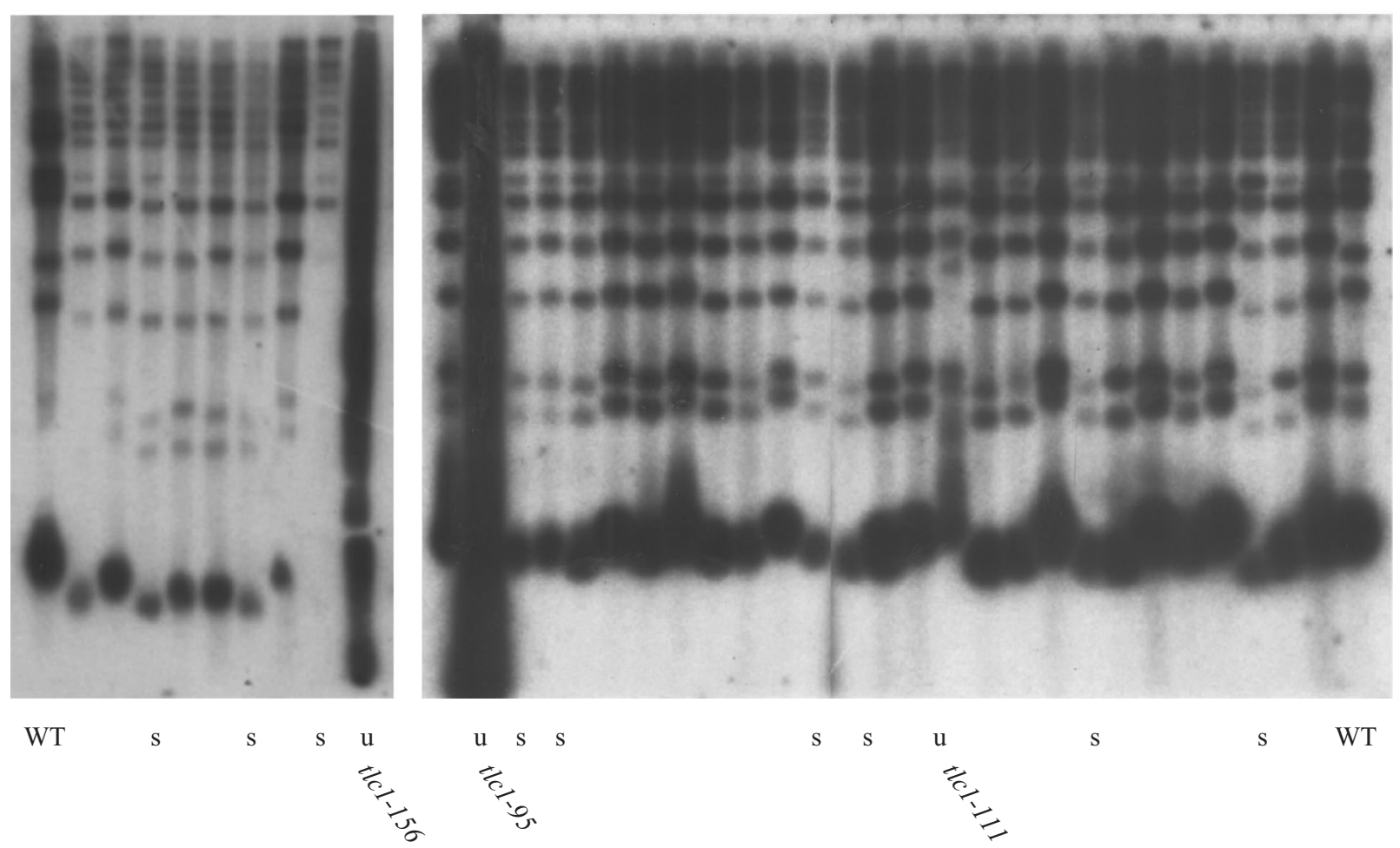

Figure 3. Telomere phenotypes caused by random mutation of the template sequence of the Saccharomyces cerevisiae telomerase RNA, TLC1. To assay the telomere phenotype of individual tlc1 template mutants, a library of random variants on a HIS3 plasmid was transformed into tlc1 cells carrying a pRS316-TLC1 plasmid. Transformants were patched onto -HIS 5'FOA plates from the -uracil (URA) -HIS transformation plate to remove the wild-type TLC1 plasmid, then serially passaged three times on -HIS plates, to analyse their growth with only the test tlc1 allele present. Single colonies were inoculated from the third -HIS plate for preparation of genomic DNA, except for senescent strains, which were inoculated from the second -HIS plate. Shown are two Southern blots showing representative telomere restriction fragment phenotypes. Genomic DNA prepared from overnight cultures inoculated from yeast extract/peptone/dextrose (YPD) plates was digested with $X h o I$ and probed with a telomeric DNA sequence oligonucleotide. Wild-type cells are labelled 'WT'. Senescent tlc1 variants are marked 's'. Variants that caused telomere elongation and/or degradation ('uncapping') are marked 'u', and given an allele number shown below the autoradiogram.

cells, and to the cellular senescence that is a hallmark of the telomerase-null phenotype (Prescott \& Blackburn 1997b).

Systematically mutating the three bases at this position in the template to all $64(4 \times 4 \times 4)$ possible sequences showed that the tlc1-476 GUG substitution was the only one that causes a telomerase-null phenotype (Lin et al. 2004). Therefore, we analysed the sensitivity of cells to other template base substitutions. The studies hitherto referred to had all used directed, site-specific mutagenesis of telomerase RNA bases. To complement this work, we carried out a survey of an unbiased set of random template mutations in $S$. cerevisiae telomerase RNA. We examined the cellular and telomere phenotypes of these mutants.

This global survey of telomerase template mutants was performed by cloning a library of tlc1 variants with mutations introduced randomly across the template domain (see table 1). Sequencing confirmed that the library of randomized mutations contained an average of 2.5 mutations per template, as predicted from its construction using randomized oligonucleotides. The telomere phenotypes of random tlc1 mutants and their ability to rescue replicative senescence in $t l c 1$ cells were tested.

Telomerase restriction fragment profiles, analysed by Southern blotting data, were classified for 156 independent mutants. Some representative examples are shown in figure 3 . Out of the 156 mutants tested, 14 had
Table 1. Telomerase RNA alleles that cause telomere dysfunction.

(The template sequence of the yeast telomerase RNA TLC1 is shown from $3^{\prime}$ to $5^{\prime}$ (nucleotides 483-468).)

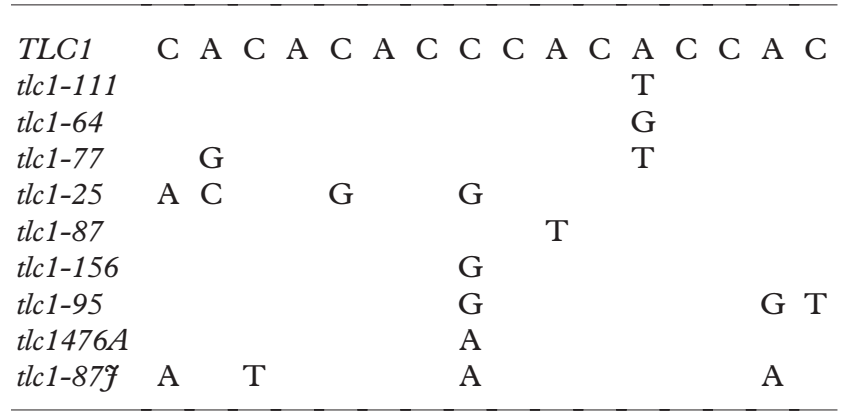

wild-type telomere length and cell growth. Thirty-one, or ca. $20 \%$, senesced with short telomeres like a control telomerase-null strain. One hundred and one had short telomeres. Out of these, we cannot exclude that some might have senesced had the experiment been extended beyond the six serial re-streaks performed in this survey experiment. Thus, randomly mutating the template domain of telomerase RNA at an average of 2.5 mutations per template causes telomere shortening in 132 out of 156 ( $c a$. $80 \%$ ) of cases, and telomerase is potentially inactivated in 
ca. $20 \%$ of these alleles. Generally similar findings have been made in an independent screen for mutations affecting the growth of yeast harbouring random template mutations (Forstemann et al. 2003).

The other template mutants analysed in the present study had long telomeres. This type of phenotype has been correlated with disruption of binding of the telomeric DNA by at least one budding yeast telomeric protein, Rap1p (Krauskopf \& Blackburn 1996; Prescott \& Blackburn 2000). Seven alleles (ca. 5\%) caused telomere 'uncapping', defined as uncontrolled elongation of telomeric DNA by telomerase. This massive telomere overelongation was accompanied by concomitant degradation of the telomeric DNA in all cases but one (tlc1-111). Examples of this telomere profile are shown in figure 3. An independent screen for telomerase RNA template mutants that cause an immediate slow growth phenotype at the colony level was also performed, using the randomized tlc1 library and directly screening several thousand colonies for growth (Chan et al. 2001). Two additional mutants with such a phenotype were found by this screen. These also caused the same phenotype of overelongated and concomitantly degraded telomeric DNA.

The total of nine 'uncapping' mutant tlc1 alleles that synthesized long and degraded telomeric DNA were sequenced and are shown in table 1. Alleles are shown in increasing order of phenotypic severity. Uncapping mutant $t l c 1-476 \mathrm{~A}$ causes slow growth and extreme telomere dysfunction and its telomeric function has been analysed in further detail (Chan et al. 2001; Smith et al. 2002; Lin et al. 2004).

Notably, the four most severe uncapping mutations contain a $\mathrm{C}$ to $\mathrm{G}$ or $\mathrm{C}$ to A transversion at nucleotide 476 (mutants, tlc1-156, tlc1-95, tlc1-476A and tlc1-87f). These mutations alter the residue corresponding to the middle G of the GGG sequence at the heart of the conserved sixbase core of the 13-base Rap1p DNA binding consensus sequence. Other mutations in this core sequence can also cause the uncapping phenotype (Lin et al. 2004).

In summary, cells and telomere length maintenance are remarkably susceptible to minor alterations of their telomerase RNA template sequence. This may be because effects on telomerase activity caused by mutating bases in the RNA template can also overlay the effects caused by disrupting telomeric protein complexes. Therefore, until we understand the interactions important for telomerase enzymatic functions, predicting a priori the phenotype that will result from any template mutation will remain uncertain.

\section{TELOMERASE AND DNA DAMAGE RESPONSES AT TELOMERES}

Under normal circumstances in dividing cells, telomerase needs to access its telomeric substrate, the telomere. A crucial finding was that the action of telomerase on telomeres is controlled by DNA damage response components, as well as by the structural components of the telomere itself. Importantly, in budding and fission yeasts, telomerase action on telomeres is promoted by DNA damage checkpoint proteins (Craven et al. 2002). These are Tel1p and Mec1p (Rad3p in Schizosaccharomyces pombe), the orthologues in these yeasts of the phosphoinositide 3kinase family members ATM and ATR. Tellp in budding yeast is dedicated largely to telomere maintenance; in humans, defective ATM leads to telomere fusions and cancer susceptibility. $\mathrm{Ku}$, a protein needed for DNA end joining of broken DNA, is also required for normal telomere maintenance by telomerase (reviewed in Chan \& Blackburn 2002).

The need for DNA damage pathway components for telomere maintenance initially seemed counterintuitive: the thinking had been that telomeres avoided being 'seen' by such components. However, the accumulated evidence indicates that DNA damage response components indeed act at telomeres, but their normal role there is to promote telomerase action, rather than DNA end-joining events. DNA damage pathway response components have been detected at telomeres of dividing cells by immunofluorescence or crosslinking methods (Zhu et al. 2000). Such findings suggest the following model: the temporary uncapping of a telomere is a regular event, occurring perhaps as often as every cell cycle. However, it is promptly corrected by telomerase action on that telomere, stimulated (by still unknown mechanisms) by the DNA damage response components that get recruited to that telomere because of its temporary uncapping. By stimulating telomerase action, the uncapping does not become irreversible.

The substrate(s) for ATM kinase/Tellp important for its action in promoting telomerase action on a telomere is not yet proved (Craven et al. 2002). Tel1p in yeast is not needed for the core enzymatic activity of the telomerase ribonucleoprotein, which can be extracted from Tellpdeleted cells and shown to have normal enzymatic activity in vitro. Instead, Tellp may act on the substrate of telomerase, the telomere, because disrupting the structure of telomeres in various ways in vivo was shown to allow telomerase action on telomeres to bypass the need for Tellp (Chan et al. 2001). Genetically, Tellp exerts its telomerase-promoting effects through the Mre11/Xrs2/ Rad50 DNA damage complex (Craven et al. 2002). This complex acts on damaged DNA, and one of its human protein components, Nijmegen breakage syndrome protein, mammalian homologue of Xrs2 (NBS1), is a substrate for human ATM kinase (Kastan et al. 2001). The MRX complex has several biochemical activities towards DNA, including endonuclease activity. Some data suggest a model in which this DNA nuclease-containing complex may act to convert the telomere into a suitable substrate for telomerase (Tsukamoto et al. 2001), which requires the single-stranded telomeric overhang. However, the mechanism by which Tel1p/ATM and the MRX complex act to promote telomerase action at telomeres is still an interesting unsolved question.

\section{PROTECTIVE ROLES OF TELOMERASE AT TELOMERES}

A population of cells from which telomerase has been experimentally removed does not immediately senesce. Instead, yeast, mice or human cells, for instance, normally have sufficient telomere length reserve that often many tens of cell divisions need to elapse before the progressive shortening of telomeres is accompanied by obvious loss of cell division capability. Thus, it might be inferred at first that lack of telomerase has no effect until telomeres shorten. However, more sensitive assays have recently revealed that 
$\mathrm{HO}$ endonuclease (GAL promoter)

HO endonuclease (GAL
modified
chromosome VII

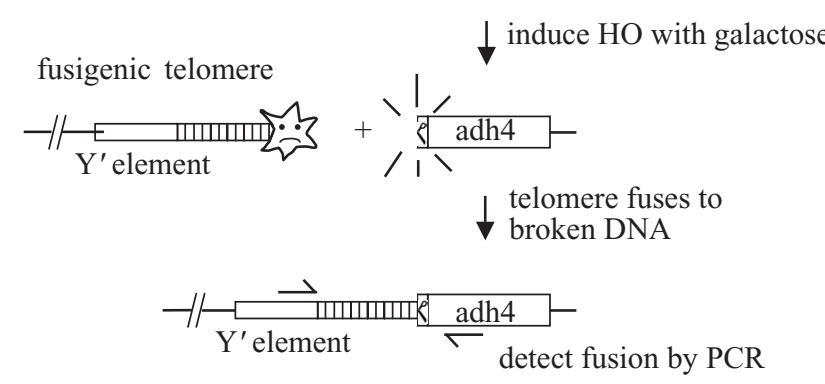

Figure 4. A direct short-term assay for telomere fusions. To produce a direct assay for fusigenic telomeres, we used a unique site on chromosome VII that is cleavable by the HO endonuclease. In this strain, the endogenous $\mathrm{HO}$ site at $M A T$ is deleted, so only one DSB is created (DuBois et al. 2002). $\mathrm{HO}$ expression was induced from the $G A L$ promoter by the addition of galactose. Fusions between a telomere and the chromosome break were detected by PCR of genomic DNA prepared from cells frozen $1-8 \mathrm{~h}$ after HO induction. Saccharomyces cerevisiae chromosomes contain either a conserved $\mathrm{X}$ or $\mathrm{Y}^{\prime}$ element next to telomeric DNA; in the complete genome sequence of the S288C strain used here there are $15 \mathrm{X}$ telomeres and $17 \mathrm{Y}^{\prime}$ telomeres. Therefore, our PCR reactions used one primer adjacent to the $\mathrm{HO}$ cleavage site on chromosome VII and a second primer complementary to either the $\mathrm{X}$ or $\mathrm{Y}^{\prime}$ subtelomeric element. Telomere shortening in the absence of telomerase can compromise chromosome end protection. For this reason, we assayed telomere-DSB fusion in cells inoculated from spore colonies, well before the onset of cellular senescence in cells lacking telomerase. (Adapted from Chan \& Blackburn (2003).)

in fact occult telomere damage is present in cells growing in the absence of telomerase (Chan \& Blackburn 2003).

The assays employed to determine the effect of telomerase on telomere integrity focused on what is arguably the most critical function of a telomere for genomic stability: its refusal to fuse to a DNA break. This protection from fusion to a broken DNA end prevents dicentric (and hence unstable) chromosomes from being generated. Because the result of a telomeric fusion is unstable, if the cell is to remain viable, additional events must then occur downstream to rearrange chromosomes so that they are no longer dicentric. To circumvent this problem, a direct assay for telomeric fusions to an induced chromosomal break was devised. This assay allowed the capture of such events within a few hours after experimentally inducing a chromosomal DNA break. The single induced chromosomal double-strand DNA break served as a 'bait' to which any uncapped telomere that happened to be in the cell could fuse (figure 4 ). Because the assay captured the immediate molecular products of such fusion by PCR, subsequent viability of the cell was not required. Importantly, therefore, the assay did not rely on the occurrence of secondary events, some of which might themselves depend on the same factors that also affect telomere fusion.

It was found that in cells growing in the absence of telomerase, even shortly after loss of telomerase (by removal of the gene encoding any telomerase component), telomeres fused to the DNA break with greatly increased frequency compared with wild-type control cells. The detected frequency of such telomere fusions was about one in a few thousand genomes. While this frequency is not enough to cause any obvious change in the gross cell population growth rate, strikingly, it was over a hundred times higher than that measured in the control wild-type cells containing telomerase: in these wild-type cells, such fusion events were detected in fewer than 1 in $10^{5}$ genomes. A telomerase point mutant lacking one of the catalytic aspartates of the RT protein component behaved like the telomerase null. Deletion of the gene for Tellp (but not of the ATR orthologue $\mathrm{Mec1}$, which is involved in DNA damage responses in yeast) also led to increased fusion. Combining the telomerase mutation with deletion or mutation of Tel1p greatly increased the frequency of fusions.

Interestingly, the fusions in the telomerase-deleted cells remained high even if the bulk telomere population had been first pre-elongated by a genetic manipulation. To make direct comparisons in these experiments, the cells were returned to the isogenic state before inducing the double-strand break and measuring the telomere fusion rates. These cells therefore differed from their respective controls (with or without telomerase) solely by having a still-elongated bulk telomere population. Thus, it could be concluded that it is the presence of the telomerase, rather than the long telomere population, that is needed to confer protection of telomeres against fusions.

The population of telomere fusions detected in these experiments was analysed. This included cloning and sequencing of the PCR products of the DNA formed by fusion of a telomere with the site of the induced DNA break. Notably, every telomere fusion event captured in this way had the same molecular characteristic: each telomere that had undergone a fusion had suffered a massive loss of most of its terminal telomeric DNA repeat tract, with only a few repeats (i.e. Rap $1 p$ binding sites) remaining at the inner end of the tract. This was seen even when the starting population of telomeres was the bulk-elongated population mentioned above. In all cases, however, the induced double-strand break had suffered little if any DNA attrition. These telomere fusion events required the normal non-homologous end-joining pathway ligase encoded by the gene DNL4, but not exonuclease I.

This work indicates that in a population of apparently healthily growing cells that lack telomerase, there are relatively rare but still significant occurrences of catastrophic telomere shortening. This occult telomere damage is present even when the bulk telomere population has been elongated. With telomerase present, the frequency of such detected events is much lower, and in wild-type cells may approach the frequency of measured chromosome loss rates $\left(c a .1\right.$ in $\left.10^{5}\right)$. Telomerase could confer protection by one or both of two mechanisms. Telomerase could prevent the drastic shortening events from occurring at all. Alternatively, they could occur even in the presence of telomerase, but telomerase rebuilds any telomere that has suffered such shortening. Such a shortened telomere is expected to elicit a DNA damage checkpoint response. It can be surmised that Tellp kinase plays a sensing or checkpoint role that is required for this response. This may help explain why the combined absence of both functional telomerase and functional Tellp causes the 
observed greatly increased frequency of telomere shortening/fusion events (Myung et al. 2001; Chan \& Blackburn 2003). Alternatively, the possible role of Tellp and the MRX complex in telomeric DNA metabolism might cause end-protection defects in cells lacking telomerase and Tellp.

How does telomerase protect telomeres? Yeast telomerase is capable of adding telomeric DNA to elongate a shortened telomere only in S or G2/M in the cell cycle (Diede \& Gottschling 1999; Marcand et al. 2000). However, surprisingly, telomerase is crosslinkable to telomeres in G1 as well as in S and G2 phases of the cell cycle, only losing measurable association with telomeres during mitosis (Taggart et al. 2002; Smith et al. 2002). Furthermore, yeast telomerases in vitro have the interesting property of staying tightly associated with their telomeric DNA polymerization product (Prescott \& Blackburn 1997a; Fulton \& Blackburn 1998). These properties suggest the possibility that telomerase may stay on telomeres even when it is not in the act of polymerizing telomeric DNA, and that such association could underlie the protective function of telomerase.

Together, these findings suggest the possibility that telomerase may have a direct role on chromosome end protection. They are of particular interest in considering the cancer-prone phenotype of humans with mutated ATM kinase. In many of the cell types that will give rise to cancers in these patients, telomerase has been repressed or downregulated as part of normal development. This combination of inactive telomerase with a lack of normal ATM function may have led to genomic instability, a hallmark of cancer. Recent results in mice lacking both telomerase and ATM support this idea (Wong et al. 2003). Such instability could arise directly from the types of events we have documented for telomeres in yeast cells lacking functional telomerase and/or Tellp.

\section{WHAT DETERMINES WHETHER A TELOMERE IS STABLE?}

\section{(a) Active telomerase allows cells to proliferate} with short telomeres

In telomerase-minus cells, gradual telomere shortening eventually leads to loss of chromosome end protection. The link between telomere shortening and cellular senescence is seen most directly by ablating the function of genes that either encode telomerase components or control telomerase action in the cell: progressive telomere shortening is accompanied by a declining rate of proliferation of the cell population (reviewed in Blackburn $2000 b$ ). Various normal somatic cells from humans, mice or chickens, which lack telomerase activity when grown in primary culture, exhibit progressive overall telomere shortening and eventual senescence of the population (that is, exit from the cell cycle). Telomere shortening was also correlated with crisis (that is, proliferation failure and cell death) of human cells whose lifespan in culture had been temporarily extended with viral oncogenes (Counter et al. 1992). Based on these observations, it was proposed that telomere shortening in these cell types is the property that limits proliferation.

Despite these seemingly straightforward inferences, an early direct indication of the complexity of telomere length regulation had already come from analyses of telomeres in different yeast strains: telomere length was clearly under the genetic control of multiple loci (Walmsley \& Petes 1985). In fact data from several systems now decisively show that a complex set of components determines what telomere length is necessary for effective telomere capping function, warning that deductions about telomere length and cell proliferative capacity can only be made when isogenicity and other conditions are strictly controlled.

Genetically well-controlled experiments in both yeasts and human cells in culture clearly showed that bulk telomere length can be uncoupled from telomere functionality. In $S$. cerevisiae cells containing only a catalytically inactive mutant telomerase RNP, essentially the entire cell population ceased dividing after a period of telomeric shortening. However, at that point, the telomeres were still significantly longer than the telomeres in otherwise isogenic cells that contained variously mutated, but still enzymatically active, telomerases: but the latter cells continued to divide indefinitely. Similar findings were made, with a different set of telomerase mutants, in another budding yeast (reviewed in Blackburn et al. 2000). These results showed that very short telomeres that otherwise would have caused cells to stop dividing stayed functional in the presence of active telomerase.

Similar results were also obtained by ectopic expression of the gene for hTERT in human cells. Such ectopic activation of telomerase in human fibroblast cells, which normally lack telomerase in culture, overcomes both senescence and crisis and allows the cells to become effectively immortalized (Bodnar et al. 1998; Zhu et al. 1999; Kim et al. 2003). Ectopically expressing wild-type hTERT results in concomitant telomere lengthening (Bodnar et al. 1998). Because telomerase-mediated telomere lengthening was associated with restoring the proliferative capability of these cells, this appeared to reinforce the link between loss of telomere function and telomere shortness. But different hTERT alleles gave a different result. Again the primary or viral oncogene-transformed human cells were immortalized, with the cells continuing to proliferate and showing fewer chromosomal end-to-end fusions than the controls that received no hTERT (Zhu et al. 1999; Kim et al. 2003). Notably, however, the bulk telomeres in the long-term proliferating cells consistently became shorter, and remained shorter, than the telomeres in control cells that were entering crisis. Hence, as with the yeast experiments, active telomerase alleles can exert a protective effect on even quite short telomeres. These results uncoupled rescue of telomeric function by telomerase from lengthening of telomeres in isogenic situations. Possible mechanisms for how active telomerase may protect short telomeres are discussed in the previous section.

\section{(b) An excess of a telomere binding protein can protect short telomeres}

A similar type of observation, in which cell proliferation was prolonged even as telomeres over-shortened, was made recently by overexpressing the protective telomere binding protein TRF2 in cultured human cells. Such overexpression in these cells, in which telomerase was not active, allowed telomere length to decline to a much shorter average length before senescence occurred than in control cells without such TRF2 overexpression 
(Karlseder et al. 2002). Hence, in this telomerase-minus setting, the excess TRF2 had a protective effect on shortened telomeres that, without it, would have been associated with cell-cycle arrest.

Many findings highlight the notion that, rather than simply being determined by telomere length, a key feature of telomeric capping is mutual reinforcement among the different molecular contributors to capping. Thus, even very short telomeres nevertheless can be permissive for continued cell proliferation if their shortness is compensated for by another factor; as just discussed, this was the ectopic expression of either telomerase or TRF2. Notably, telomerase is strongly upregulated in the majority of proliferating human cancer cells, but their telomeres are typically much shorter than those in their normal cell progenitors (Meeker et al. 2002).

\section{(c) Compromised telomeres can be readily} uncapped

Conversely, many data indicate that while a mutation compromising or abrogating any one component of the capping system can be harmless by itself, combining it with another such singly harmless mutation can cause failure of cap functions. For example, in experiments in the budding yeast Kluyveromyces lactis, synergistic catastrophic loss of telomere capping in a large fraction of cells could be caused in this way. A small mutation in the Rap1p domain that is involved in forming the higher-order telomeric complex on yeast telomeres was harmless by itself. Similarly, a particular telomerase RNA template mutation modestly decreased Rap1p binding affinity to the DNA in vitro and had only a barely discernible effect on long-term telomere maintenance in vivo. However, when the two mutations were combined in the cell, over several cell divisions the population of telomeres gradually converted to a completely uncapped state. The consequences of combining the two mutations were that the telomeric DNA became overelongated and simultaneously degraded, and cell viability was significantly diminished (Krauskopf \& Blackburn 1996, 1998; Smith \& Blackburn 1999).

\section{TELOMERE LENGTH: NOT THE CRYSTAL BALL FOR READING A CELL'S FATE}

Telomere length of human cells is readily measured experimentally, and thus has often been used as a criterion to try to deduce cellular proliferation history and future potential. For example, the short telomeres often seen in cancer cells were taken as evidence that the cells had gone through many rounds of replication and therefore had undergone telomerase activation late in the progression of tumorigenesis (Hastie et al. 1990). In some studies, average telomere length in $\mathrm{T}$ cells has been used as an indicator of the number of times these $\mathrm{T}$ cells had divided (Hodes et al. 2002).

A central premise of these and many other studies had been that a fixed degree of average loss of telomeric DNA occurs each time a cell divides. In non-immortalized cells with no detectable telomerase in cell culture, so long as cell type, isogenicity and certain growth conditions are fixed, this assumption has an experimentally demonstrated basis. But, for example, variable levels of oxidative stress correlate with increased telomere shortening rates
(Von Zglinicki 2002). Even more importantly, the premise becomes useless if telomerase is active, because telomerase action elongates telomeres. Telomerase is active in a variety of different normal human somatic cell types, where it can 'top up' telomeric DNA by adding extra telomeric DNA sequences (Roelofs et al. 2003). This contradicts an often-pervasive assumption that telomerase is not active in normal somatic (non-germline) tissues of adult humans. Hence, in cells with telomerase, shortening of telomeric DNA cannot be used as a measure of the number of cell divisions. In other words, if telomere length is to be likened to a mitotic 'clock' that counts down the cell divisions, activating telomerase simply moves the hands of the clock back.

Simple models correlating telomere length with proliferative potential also overlook developmental regulation of telomere length, which remains poorly characterized. Several studies show that in proliferating somatic mammalian cells types with active or readily activatable telomerase, a relationship between telomere shortening and organismal age can be lost. For example, normal human $\mathrm{T}$ and $\mathrm{B}$ cells at various stages of maturation activate their telomerase. These cells include mature $\mathrm{T}$ cells that have been stimulated to divide, as well as $\mathrm{T}$ and $\mathrm{B}$ cells at other developmental stages. In peripheral blood mononucleocytes and other cells of the lymphatic system, telomeres in some cell populations rapidly shorten in infants and pre-school children, and then the shortening rate per cell division slows (Frenck et al. 1998). In certain stages of the maturation of B cells, telomeres actually lengthen as these cells proliferate (Hodes et al. 2002). In the African clawed toad, telomeres are longer in adult spleens than in the testis or early embryos (Bassham et al. 1998).

In summary, the emerging understanding of the multiple determinants of telomere capping has eroded the simple concept of a critical telomere length, which often will fail to predict telomere functionality unless genetic and other conditions are held strictly constant. Furthermore, more complete data now show that an earlier assumption that telomerase is inactive in normal somatic cells, and therefore that telomere length erosion is always a measure of the number of times a cell has divided, can be misleading.

\section{IMPLICATIONS}

A question was posed by the physicist Freeman Dyson: 'Why is life so complicated?' (Dyson 1999, p. 72). He posited that one answer lies in the need for homeostatic systems in living cells, because homeostasis, with its capacity for self-correction, inherently demands inbuilt complexity (Dyson 1999). Mechanistically, the problem of DNA end replication can be solved simply, as seen in viruses, for example, by means of a covalent terminal protein or DNA hairpin ends. However, such solutions to the problem of DNA end replication have little or no inbuilt mechanism for error correction. By contrast, the available evidence suggests that telomeres and telomerase together constitute an elaborate cellular homeostatic subsystem, in which telomere length and integrity are closely monitored and tightly controlled. Furthermore, new results call for rethinking of some previously held ideas about telomeres. For example, telomere length is readily measured exper- 
imentally and had become used to deduce both the proliferation history and the replicative potential of a cell. Short telomeres were often taken as prima facie evidence that the cells had gone through many rounds of replication and would have a limited future replicative potential. Telomere length in cells of the immune system has been used to try to predict whether these cells can keep proliferating, for example, after clinical transplantation. But in many situations telomere length is a misleading prophet of a cell's proliferative potential. Instead, multiple molecular factors, including the presence of functional telomerase, can determine whether a telomere is capped.

Major questions about telomeres and telomerase remain: how do telomerase, the DNA damage response pathways and the different components of telomeres combine to ensure telomeric and hence genomic stability? We know many of the players in this cellular drama: how do they act together? What is the precise molecular nature of the two telomeric states? As complex biological processes are being understood at increasingly sophisticated levels, a view has emerged that many seemingly deterministic phenomena in biology can be explained as stochastic stabilization of one of two functionally different physical states (Kirschner $e t$ al. 2000). Another example of this may be provided by the capped and uncapped states of telomeres.

These considerations of telomere function can be extended farther afield. For instance, what are the implications of telomere functioning for cloning mammals? When young, the cloned sheep Dolly had telomeres that were shorter than those of her adult mother. Cloned cow telomeres, however, were longer than those of the parental animal (Mollard et al. 2002). Although different in length from their adult mothers', these telomeres in the cloned progeny almost certainly had been acted upon by telomerase during their embryogenesis, as telomerase is widely active in mammalian embryonic tissues. Given the complexity of factors that determine whether a telomere is functional, Dolly's shortened telomeres may still have fallen within a length range compatible with normal function. Thus it is not clear whether her shortened telomeres spelled her early demise, or presage a limit to the number of times that cloned animals can produce progeny.

What are the implications for medicine? Much still needs to be learned about telomere functions in the whole human body. Intriguingly, though, human mortality rates from various causes including cardiovascular disease and infections are higher in elderly individuals with shorter average telomere length in their blood cells than in people with longer telomeres (Cawthon et al. 2003). Cause and effect are unknown here. How the various components of telomeres interact is clearly important in the lives of human cells, because such interactions can have large impacts on the proliferation of both healthy and cancerous human cells. Ectopic expression of telomerase in human cells cultured in vitro overcomes cellular senescence. Haploinsufficiency for telomerase in humans RNA leads to early mortality through bone marrow failure (Vulliamy et al. 2001). Therefore, controlling the proliferative potential of normal human cells with telomerase may conceivably allow cellular regeneration for medical uses. But first understanding how telomeres function and how telomerase exerts its protective effects will be necessary if telomeres and telomerase are to be manipulated effectively.

\section{MATERIAL AND METHODS}

To create a library of telomerase RNA (TLC1) genes containing random template mutations, randomized oligonucleotides were used. These oligonucleotides contained an average of 2.5 mutations per template as calculated from the relative proportions of nucleotide precursors used in oligonucleotide synthesis. The library was constructed on a HIS3 plasmid and had a complexity of $c a .2 \times 10^{4}$. A small aliquot of the library was plated and a colony hybridization was performed to estimate how much of the library was similar to wild-type sequences: probably generated by re-ligation of the vector during cloning steps. Eleven colonies from a total of 79 hybridized strongly to a wild-type probe after $2 \times 5 \mathrm{~min}$ washes at $55^{\circ} \mathrm{C}$. Thus, a maximum of $c a .15 \%$ of the library may have contained wildtype TLC1 genes.

The library was transformed into a $t c 1$ strain, selected against a covering TLC1 URA3-marked plasmid on 5'FOA-HIS, and transformants were grown for two additional passages on -HIS plates, then Southern blotted for telomeric DNA to analyse the telomere phenotype caused by the mutant telomerase RNAs. Replicative senescence was assayed by streaking these cells for four additional passages on -HIS plates (a total of six streaks) and recording the growth phenotype.

The authors gratefully acknowledge support to E.H.B. for the work described here from the National Institutes of Health (grant GM26259) and from the Steven and Michelle Kirsch Foundation. S.R.W.L.C. was supported by a Howard Hughes Medical Institute Predoctoral Fellowship.

\section{REFERENCES}

Bassham, S., Beam, A. \& Shampay, J. 1998 Telomere variation in Xenopus laevis. Mol. Cell. Biol. 18, 269-275.

Blackburn, E. H. 1991 Telomeres. Trends Biochem. Sci. 16, 378-381.

Blackburn, E. H. 1999 Telomerase. In The RNA world II (ed. R. F. Gesteland \& J. F. Atkins), pp. 609-635. Cold Spring Harbor, NY: Cold Spring Harbor Laboratory.

Blackburn, E. H. $2000 a$ The end of the (DNA) line. Nature Struct. Biol. 7, 847-850.

Blackburn, E. H. $2000 b$ Telomere states and cell fates. Nature 408, 53-56.

Blackburn, E. H. 2001 Switching and signaling at the telomere. Cell 106, 661-673.

Blackburn, E. H. \& Szostak, J. W. 1984 The molecular structure of centomeres and telomeres. A. Rev. Biochem. 53, 163-194.

Blackburn, E. H., Chan, S., Chang, J., Fulton, T. B., Krauskopf, A., McEachern, M., Prescott, J., Roy, J., Smith, C. \& Wang, H. 2000 Molecular manifestations and molecular determinants of telomere capping. In Cold Spring Harbor Symposia on Quantitative Biology: Biological responses to DNA damage. pp. 253-263. Cold Spring Harbor, NY: Cold Spring Harbor Laboratory Press.

Blasco, M. A. 2002 Telomerase beyond telomeres. Nature Rev. Cancer 2, 627-633.

Bodnar, A. G., Ouellette, M., Frolkis, M., Holt, S. E., Chiu, C., Morin, M., Harley, C. B., Shay, J. W., Lichtsteiner, S. \& Wright, W. E. 1998 Extension of lifespan by introduction of telomerase into normal human cells. Science 279, 349-352.

Cawthon, R. M., Smith, K. R., O’Brien, E., Sivatchenko, A. \& Kerber, R. A. 2003 Association between telomere length in blood and mortality in people aged 60 years or older. Lancet 361, 393-395. 
Cenci, G., Siriaco, G., Raffa, G. D., Kellum, R. \& Gatti, M. 2003 The Drosophila HOAP protein is required for telomere capping. Nature Cell Biol. 5, 82-84.

Chan, S. W. \& Blackburn, E. H. 2002 New ways not to make ends meet: telomerase, DNA damage proteins and heterochromatin. Oncogene 21, 553-563.

Chan, S. W. \& Blackburn, E. H. 2003 Telomerase and the ATM homolog Tellp protect telomeres from fusing to an induced double-stranded break. Mol. Cell 5, 1379-1387.

Chan, S. W., Chang, J., Prescott, J. \& Blackburn, E. H. 2001 Altering telomere structure allows telomerase to act in yeast lacking ATM kinases. Curr. Biol. 11, 1240-1250.

Cohn, M. \& Blackburn, E. H. 1995 Telomerase in yeast. Science 269, 396-400.

Conrad, M. N., Wright, J. H., Wolf, A. J. \& Zakian, V. A. 1990 RAP1 protein interacts with yeast telomeres in vivo: overproduction alters telomere structure and decreases chromosome stability. Cell 63, 739-750.

Cooper, J. P., Nimmo, E. R., Allshire, R. C. \& Cech, T. R. 1997 Regulation of telomere length and function by a Mybdomain protein in fission yeast. Nature 385, 744-747.

Counter, C. M., Avilion, A. A., LeFeuvre, C. E., Stewart, N. G., Greider, C. W., Harley, C. B. \& Bacchetti, S. 1992 Telomere shortening associated with chromosome instability is arrested in immortal cells which express telomerase activity. EMBO F. 11, 1921-1929.

Craven, R. J., Greenwell, P. W., Dominska, M. \& Petes, T. D. 2002 Regulation of genome stability by TEL1 and MEC1, yeast homologs of the mammalian ATM and ATR genes. Genetics 161, 493-507.

Diede, S. J. \& Gottschling, D. E. 1999 Telomerase-mediated telomere addition in vivo requires DNA primase and DNA polymerases alpha and delta. Cell 99, 723-733.

DuBois, M. L., Haimberger, Z.W., McIntosh, M. W. \& Gottschling, D. E. 2002 A quantitative assay for telomere protection in Saccharomyces cerevisiae. Genetics 161, 995-1013.

Dyson, F. 1999 Origins of life, 2nd edn. Cambridge University Press.

Forstemann, K., Zaug, A. J., Cech, T. R. \& Lingner, J. 2003 Yeast telomerase is specialized for C/A-rich RNA templates. Nucleic Acids Res. 31, 1646-1655.

Frenck Jr, R. W., Blackburn, E. H. \& Shannon, K. M. 1998 The rate of telomere sequence loss in human leukocytes varies with age. Proc. Natl Acad. Sci. USA 95, 5607-5610.

Fulton, T. B. \& Blackburn, E. H. 1998 Identification of Kluyveromyces lactis telomerase: discontinuous synthesis along the 30-nucleotide-long templating domain. Mol. Cell. Biol. 18, 4961-4970.

Gilley, D. \& Blackburn, E. H. 1996 Specific RNA residue interactions required for enzymatic functions of Tetrahymena telomerase. Mol. Cell. Biol. 16, 66-75.

Gilley, D., Lee, M. S. \& Blackburn, E. H. 1995 Altering specific telomerase RNA template residues affects active site function. Genes Dev. 9, 2214-2226.

Greider, C. W. \& Blackburn, E. H. 1985 Identification of a specific telomere terminal transferase activity in Tetrahymena extracts. Cell 43, 405-413.

Greider, C. W. \& Blackburn, E. H. 1987 The telomere terminal transferase of Tetrahymena is a ribonucleoprotein enzyme with two distinct primer specificity components. Cell 51, 887-898.

Greider, C. W. \& Blackburn, E. H. 1989 A telomeric sequence in the RNA of Tetrahymena telomerase required for telomere repeat synthesis. Nature 337, 331-337.

Hastie, N. D., Dempster, M., Dunlop, M. G., Thompson, A. M., Green, D. K. \& Allshire, R. C. 1990 Telomere reduction in human colorectal carcinoma and with ageing. Nature 346, 866-868.
Hodes, R. J., Hathcock, K. S. \& Weng, N. P. 2002 Telomeres in $\mathrm{T}$ and B cells. Nature Rev. Immunol. 2, 699-706.

Karlseder, J., Smogorzewska, A. \& de Lange, T. 2002 Senescence induced by altered telomere state, not telomere loss. Science 295, 2446-2449.

Kastan, M. B., Lim, D. S., Kim, S. T. \& Yang, D. 2001 ATM: a key determinant of multiple cellular responses to irradiation. Acta Oncol. 40, 686-688.

Kim, M. M., Rivera, M. A., Botchkina, I. L., Shalaby, R., Thor, A. D. \& Blackburn, E. H. 2001 A low threshold level of expression of mutant-template telomerase RNA inhibits human tumor cell proliferation. Proc. Natl Acad. Sci. USA 98, 7982-7987.

Kim, M. M., Xu, L. \& Blackburn, E. H. 2003 Catalytically normal human telomerase mutants with allele-specific biological properties. Exp. Cell Res. 288, 277-287.

Kim, S. H., Kaminker, P. \& Campisi, J. 1999 TIN2, a new regulator of telomere length in human cells. Nature Genet. 23, 405-412.

Kirschner, M., Gerhart, J. \& Mitchison, T. 2000 Molecular 'vitalism'. Cell 100, 79-88.

Krauskopf, A. \& Blackburn, E. H. 1996 Control of telomere growth by interactions of RAP1 with the most distal telomeric repeats. Nature 383, 354-357.

Krauskopf, A. \& Blackburn, E. H. 1998 Rap1 protein regulates telomere turnover in yeast. Proc. Natl Acad. Sci. USA 95, 12 486-12 491.

Laroche, T., Martin, S. G., Tsai-Pflugfelder, M. \& Gasser, S. M. 2000 The dynamics of yeast telomeres and silencing proteins through the cell cycle. F. Struct. Biol. 129, 159-174.

Lee, M. S. \& Blackburn, E. H. 1993 Sequence-specific DNA primer effects on telomerase polymerization activity. Mol. Cell. Biol. 13, 6586-6599.

Lin, J., Smith, D. L. \& Blackburn, E. H. 2004 Mutant telomere sequences lead to impaired chromosome separation and a unique checkpoint response. Mol. Biol. Cell. (Submitted.)

Lingner, J., Hughes, T. R., Shevchenko, A., Mann, M., Lundblad, V. \& Cech, T. R. 1997 Reverse transcriptase motifs in the catalytic subunit of telomerase. Science 276, 561-567.

Ly, H., Xu, L., Rivera, M. A., Parslow, T. G. \& Blackburn, E. H. 2003a A role for a novel 'trans-pseudoknot' RNARNA interaction in the functional dimerization of human telomerase. Genes Dev. 17, 1078-1083.

Ly, H., Blackburn, E. H. \& Parslow, T. G. 20036 Comprehensive structure-function analysis of the core domain of human telomerase RNA. Mol. Cell. Biol. 23, 6849-6856.

McClintock, B. 1938 The fusion of broken ends of sister halfchromatids following chromatid breakage at meiotic anaphase. Res. Bull. Mo. Agric. Esp. Stn. 290, 1-48.

McClintock, B. 1941 The stability of broken ends of chromosomes in Zea mays. Genetics 26, 234-282.

McClintock, B. 1942 The fusion of broken ends of chromosomes following nuclear fusion. Proc. Natl Acad. Sci. USA 28, 458-463.

McCormick-Graham, M. \& Romero, D. P. 1996 A single telomerase RNA is sufficient for the synthesis of variable telomeric DNA repeats in ciliates of the genus Paramecium. Mol. Cell. Biol. 16, 1871-1879.

McEachern, M. J. \& Blackburn, E. H. 1995 Runaway telomere elongation caused by telomerase RNA gene mutations. Nature 376, 403-409.

McEachern, M. J., Krauskopf, A. \& Blackburn, E. H. 2000 Telomeres and their control. A. Rev. Genet. 34, 331-358.

Marcand, S., Gilson, E. \& Shore, D. 1997 A protein-counting mechanism for telomere length regulation in yeast. Science 275, 986-990. 
Marcand, S., Brevet, V., Mann, C. \& Gilson, E. 2000 Cell cycle restriction of telomere elongation. Curr. Biol. 10, 487-490.

Meeker, A. K., Hicks, J. L., Platz, E. A., March, G. E., Bennett, C. J., Delannoy, M. J. \& De Marzo, A. M. 2002 Telomere shortening is an early somatic DNA alteration in human prostate tumorigenesis. Cancer Res. 62, 6405-6409.

Mitton-Fry, R. M., Anderson, E. M., Hughes, T. R., Lundblad, V. \& Wuttke, D. S. 2002 Conserved structure for singlestranded telomeric DNA recognition. Science 296, 145-147.

Mollard, R., Denham, M. \& Trounson, A. 2002 Technical advances and pitfalls on the way to human cloning. Differentiation 70, 1-9.

Muller, H. J. 1938 The remaking of chromosomes. Collecting Net. 13, 182-198.

Muller, H. J. \& Herskowitz, I. H. 1954 Concerning the healing of chromosome ends produced by breakage in Drosophila melanogaster. Am. Nat. 88, 177-208.

Myung, K., Chen, C. \& Kolodner, R. D. 2001 Multiple pathways cooperate in the suppression of genome instability in S. cerevisiae. Nature 411, 1073-1076.

Nakamura, T. M. \& Cech, T. R. 1998 Reversing time: origin of telomerase. Cell 92, 587-590.

Nakamura, T. M., Morin, G. B., Chapman, K. B., Weinrich, S. L., Andrews, W. H., Lingner, J., Harley, C. B. \& Cech, T. R. 1997 Telomerase catalytic subunit homologs from fission yeast and human. Science 277, 955-959.

Olovnikov, A. M. 1973 A theory of marginotomy. F. Theor. Biol. 41, 181-190.

Pardue, M. L. 1995 Drosophila telomeres: another way to end it all. In Telomeres (ed. E. H. Blackburn \& C. W. Greider), pp. 339-370. Cold Spring Harbor, NY: Cold Spring Harbor Laboratory Press.

Prescott, J. \& Blackburn, E. H. 1997 a Functionally interacting telomerase RNAs in the yeast telomerase complex. Genes Dev. 11, 2790-2800.

Prescott, J. \& Blackburn, E. H. $1997 b$ Telomerase RNA mutations in Saccharomyces cerevisiae alter telomerase action and reveal nonprocessivity in vivo and in vitro. Genes Dev. 11, 528-540.

Prescott, J. C. \& Blackburn, E. H. 2000 Telomerase RNA template mutations reveal sequence-specific requirements for the activation and repression of telomerase action at telomeres. Mol. Cell. Biol. 20, 2941-2948.

Rivera, M. A. \& Blackburn, E. H. 2004 Processive utilization of the human telomerase template: lack of a requirement for template switching. Mol. Cell. Biol. (Submitted.)

Roelofs, H., de Pauw, E. S., Zwinderman, A. H., Opdam, S. M., Willemze, R., Tanke, H. J. \& Fibbe, W. E. 2003 Homeostasis of telomere length rather than telomere shortening after allogeneic peripheral blood stem cell transplantation. Blood 101, 358-362.

Roy, J., Fulton, T. B. \& Blackburn, E. H. 1998 Specific telomerase RNA residues distant from the template are essential for telomerase function. Genes Dev. 12, 3286-3300.

Shippen-Lentz, D. \& Blackburn, E. H. 1990 Functional evidence for an RNA template in telomerase. Science 247, $546-552$.

Singer, M. S. \& Gottschling, D. E. 1994 TLC1: template RNA component of Saccharomyces cerevisiae telomerase. Science 266, 404-409.

Smith, C. D. \& Blackburn, E. H. 1999 Uncapping and deregulation of telomeres lead to detrimental cellular consequences in yeast. F. Cell Biol. 145, 203-214.

Smith, C. D., Smith, D. L., DeRisi, J. L. \& Blackburn, E. H. 2002 Telomeric protein distributions and remodeling through the cell cycle in S. cerevisiae. Mol. Biol. Cell 14, $556-570$
Taggart, A. K., Teng, S. C. \& Zakian, V. A. 2002 Est1p as a cell cycle-regulated activator of telomere-bound telomerase. Science 297, 1023-1026.

Tsukamoto, Y., Taggart, A. K. \& Zakian, V. A. 2001 The role of the Mre11-Rad50-Xrs2 complex in telomerase-mediated lengthening of Saccharomyces cerevisiae telomeres. Curr. Biol. 11, 1328-1335.

Tzfati, Y., Knight, Z., Roy, J. \& Blackburn, E. H. 2003 A novel pseudoknot element is essential for the action of a yeast telomerase. Genes Dev. 17, 1779-1788.

Van Steensel, B. \& de Lange, T. 1997 Control of telomere length by the human telomeric protein TRF1. Nature 385, $740-743$.

Von Zglinicki, T. 2002 Oxidative stress shortens telomeres. Trends Biochem. Sci. 27, 339-344.

Vulliamy, T., Marrone, A., Goldman, F., Dearlove, A., Bessler, M., Mason, P. J. \& Dokal, I. 2001 The RNA component of telomerase is mutated in autosomal dominant dyskeratosis congenita. Nature 413, 432-435.

Walmsley, R. M. \& Petes, T. D. 1985 Genetic control of chromosome length in yeast. Proc. Natl Acad. Sci. USA 82, 506-510.

Ware, T. L., Wang, H. \& Blackburn, E. H. 2000 Three telomerases with completely non-telomeric template replacements are catalytically active. EMBO f. 19, 3119-3131.

Wellinger, R. J., Ethier, K., Labrecque, P. \& Zakian, V. A. 1996 Evidence for a new step in telomere maintenance. Cell 85, 423-433.

Wong, K. K., Maser, R. S., Bachoo, R. M., Menon, J., Carrasco, D. R., Gu, Y., Alt, F. W. \& DePinho, R. A. 2003 Telomere dysfunction and ATM deficiency compromises organ homeostasis and accelerates ageing. Nature 421, 643-648.

Wotton, D. \& Shore, D. 1997 A novel Rap1p-interacting factor, Rif2p, cooperates with Rif1p to regulate telomere length in Saccharomyces cerevisiae. Genes Dev. 11, 748-760.

Yu, G. L., Bradley, J. D., Attardi, L. D. \& Blackburn, E. H. 1990 In vivo alteration of telomere sequences and senescence caused by mutated Tetrahymena telomerase RNAs. Nature 344, 126-132.

Zhu, J., Wang, H., Bishop, J. M. \& Blackburn, E. H. 1999 Telomerase extends the lifespan of virus-transformed human cells without net telomere lengthening. Proc. Natl Acad. Sci. USA 96, 3723-3728.

Zhu, X. D., Kuster, B., Mann, M., Petrini, J. H. \& de Lange, T. 2000 Cell-cycle-regulated association of RAD50/MRE11/ NBS1 with TRF2 and human telomeres. Nature Genet. 25, $347-352$.

\section{GLOSSARY}

ATM: Ataxia telangiectasia mutated, a DNA damagesensing kinase

ATR: ATM-related, a DNA damage-sensing kinase

DSB: double-strand break

5'-FOA: 5'-fluoroorotic acid

HIS: histidine

HO: Saccharomyces cerevisiae mating type-switching endonuclease

hTERT: human telomerase RT protein

MRX: Mre11/Rad50/Xrs2, a DNA damage response complex

RNP: ribonucleoprotein

$\mathrm{RT}$ : reverse transcriptase

TER: telomerase RNA

TERT: telomerase RT protein

TLC1: Saccharomyces cerevisiae telomerase RNA

TRF2: telomere repeat-binding factor 